\title{
2014 Gabriella E. Molnar-Swafford Pediatric PM\&R Lifetime Achievement Award
}

The Pediatric PM\&R Lifetime Achievement Award was created in 2013 to honor a physiatrist who has made exceptional contributions to pediatric rehabilitation medicine; the inaugural recipient was Dr. Michael Alexander. The purpose of the Award is to recognize the leaders in the field of pediatric rehabilitation who have followed in the footsteps of Dr. Gabriella Molnar.

Nominee must be a physiatrist whose career has been primarily or entirely in pediatric rehabilitation. The candidate should have made significant contributions to the field through education, research and/or leadership. Eligible individuals must be residents of the United States. Candidate must be notified of the nomination in advance and must agree that his/her name and image be used for publicity purposes should s/he win the Award, and will travel to accept the Award. The recipient of the Award will receive a $\$ 1,000$ honorarium and their travel expenses will be paid (round-trip coach airfare and one night hotel accommodation) to accept the award at the AAPM\&R Annual Assembly in San Diego.
A letter of nomination must be submitted in writing and received by the Foundation for PM\&R by June $1^{\text {st }}, 2014$. The winner of the Award will be notified by August 15, 2014. Nominations can be sent to: Phyllis J. Anderson, Executive Director, Foundation for PM\&R, 9700 W. Bryn Mawr Ave, Suite 200, Rosemont, IL 60018; fax 847-737-6063; e-mail: panderson@foundationforpmr.org.

\section{NEW MOLNAR TRANSITIONAL CARE RESEARCH GRANT}

The Foundation for PM\&R is pleased to announce a new Gabriella Molnar-Swafford Transitional Care Research Grant with an application deadline of May 1, 2014. The award is $\$ 10,000$ for research into the best practices, models of care and outcomes when transitioning young adults with childhood onset disability into the adult healthcare world. Complete details about the grant criteria and the application form can be found on the Foundation website at www.foundationforpmr. org. 